\title{
RESEARCH
}

\section{Peptide receptor radionuclide therapy in gastroenteropancreatic NEN G3: a multicenter cohort study}

\author{
Esben Andreas Carlsen 1,2, Nicola Fazio33, Dan Granberg4, Simona Grozinsky-Glasberg5, Hojjat Ahmadzadehfar6, \\ Chiara Maria Grana7, Wouter T Zandee ${ }^{8}$, Jaroslaw Cwikla ${ }^{9}$, Martin A Walter ${ }^{10}$, Peter Sandor Oturai1, Anja Rinke ${ }^{11}$, \\ Andrew Weaver ${ }^{12}$, Andrea Frilling ${ }^{13}$, Sara Gritti³ ${ }^{3}$ Anne Kirstine Arveschoug ${ }^{14}$, Amichay Meirovitz ${ }^{15}$, Ulrich Knigge ${ }^{2,16}$ \\ and Halfdan Sorbye ${ }^{17,18}$
}

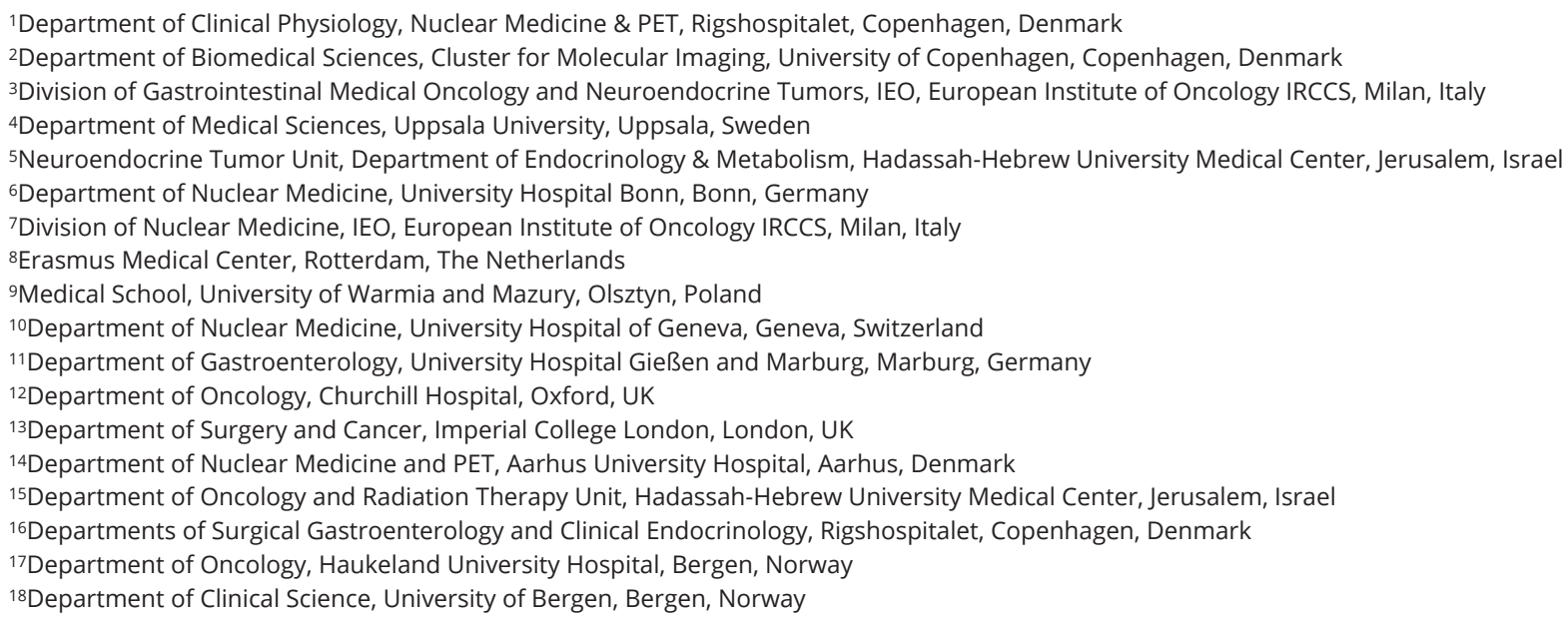

Correspondence should be addressed to E A Carlsen: esben.a.carlsen@gmail.com

\begin{abstract}
Peptide receptor radionuclide therapy (PRRT) is an established treatment of metastatic neuroendocrine tumors grade 1-2 (G1-G2). However, its possible benefit in high-grade gastroenteropancreatic (GEP) neuroendocrine neoplasms (NEN G3) is largely unknown. We therefore aimed to assess the benefits and side effects of PRRT in patients with GEP NEN G3. We performed a retrospective cohort study at 12 centers to assess the efficacy and toxicity of PRRT in patients with GEP NEN G3. Outcomes were response rate, disease control rate, progression-free survival (PFS), overall survival (OS) and toxicity. We included 149 patients (primary tumor: pancreatic $n=89$, gastrointestinal $n=34$, unknown $n=26)$. PRRT was first-line $(n=30)$, second-line $(n=62)$ or later-line treatment $(n=57)$. Of 114 patients evaluated, $1 \%$ had complete response, $41 \%$ partial response, $38 \%$ stable disease and $20 \%$ progressive disease. Of 104 patients with documented progressive disease before PRRT, disease control rate was $69 \%$. The total cohort had median PFS of 14 months and OS of 29 months. Ki-67 21-54\% $(n=125)$ vs Ki- $67 \geq 55 \%$ $(n=23)$ : PFS 16 vs 6 months $(P<0.001)$ and OS 31 vs 9 months $(P<0.001)$. Well $(n=60)$ vs poorly differentiated NEN ( $n=62)$ : PFS 19 vs 8 months $(P<0.001)$ and OS 44 vs 19 months $(P<0.001)$. Grade $3-4$ hematological or renal toxicity occurred in $17 \%$ of patients.
\end{abstract}

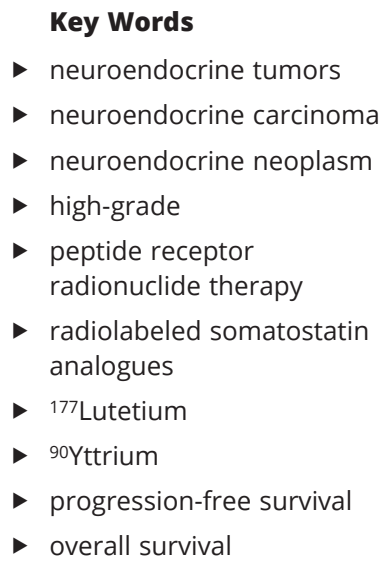

C) 2019 Society for Endocrinology Published by Bioscientifica Ltd. Printed in Great Britain 
This large multicenter cohort of patients with GEP NEN G3 treated with PRRT demonstrates promising response rates, disease control rates, PFS and OS as well as toxicity in patients with mainly progressive disease. Based on these results, PRRT may be considered for patients with GEP NEN G3.

\section{Introduction}

Neuroendocrine neoplasms (NENs) are a very heterogeneous entity classified according to primary tumor location, stage, proliferation rate and differentiation. The 2010 World Health Organization (WHO) Classification grades NEN according to the proliferation index Ki-67; $\leq 2 \%$ (Grade 1, G1), 3-20\% (G2) and $>20 \%$ (G3) (Bosman et al. 2010). G1-G2 was collectively referred to as neuroendocrine tumors (NET) and G3 as neuroendocrine carcinoma (NEC). The classification is strongly prognostic, but is also used to guide treatment decisions. In 2017, WHO refined the classification of pancreatic NEN; G3 tumors are further classified as well (NET G3) and poorly differentiated (NEC) based on morphology (Kloppel et al. 2017), and a similar expansion to gastrointestinal (GI) G3 tumors is anticipated in the next WHO classification. The NET category is now only used for well-differentiated tumors regardless of their proliferation index (G1-G3), whereas the NEC category is used for poorly differentiated high-grade neuroendocrine carcinomas (G3). The terminology of NEN G3 relates to all high-grade (G3, Ki-67 >20\%) neuroendocrine malignancies; i.e. both NET G3 and NEC.

Gastroenteropancreatic (GEP) NENs G3 are rare, highly malignant, with poor prognosis and limited therapeutic options (Sorbye et al. 2014, Ilett et al. 2015, Garcia-Carbonero et al. 2016). The majority of patients have metastases at the time of diagnosis and median overall survival (OS) is less than 6 months including all patients (Dasari et al. 2018). Platinum-based chemotherapy is the standard treatment in metastatic disease with response rates of 30-35\%, progression-free survival (PFS) of 4-5 months and OS 11-14 months (Sorbye et al. 2013, Yamaguchi et al. 2014, Heetfeld et al. 2015, Walter et al. 2017).

In metastatic GEP NET G1-G2, peptide receptor radionuclide therapy (PRRT) targeting somatostatin receptors has been used with excellent results for the last two decades in Europe and Israel (Kwekkeboom et al. 2008, Bodei et al. 2011, Imhof et al. 2011, Pfeifer et al. 2011, Romer et al. 2014). The recent NETTER-1 phase 3 trial of patients with somatostatin receptor imaging (SRI)-positive NET G1/G2 supports this approach (Strosberg et al. 2017). In contrast, PRRT has generally not been recommended for GEP NEN G3 based on expectance of low expression of somatostatin receptors and rapid growth behavior. According to guidelines, PRRT can be considered in SRI-positive NET G3, but data are lacking (Garcia-Carbonero et al. 2016). PRRT could, however, be a relevant therapeutic option for NEN G3 since SRI positivity has been reported for both NET G3 and NEC (Sorbye et al. 2013, Velayoudom-Cephise et al. 2013, Heetfeld et al. 2015, Raj et al. 2017), as well as having expression of somatostatin receptor $2 \mathrm{~A}$ on immunohistochemistry (Konukiewitz et al. 2017).

Randomized large studies to assess the benefit of specific treatments are often not feasible to perform in very rare diseases. Large retrospective datasets may then initially be the only way on which to base treatment decisions. In a large multicenter international cooperation, we therefore collected retrospectively the outcomes after PRRT in patients with GEP NEN G3.

\section{Methods}

\section{Patients}

At 12 university hospitals, we retrospectively included patients that fulfilled the following criteria: (1) GEP NEN or NEN of unknown primary with dominance of abdominal metastases, (2) Ki-67 $>20 \%$ and (3) treated with PRRT. Data on demographics, diagnosis, previous treatments, PRRT, outcome and toxicity were registered. SRI ( ${ }^{68} \mathrm{Ga}$-somatostatin analogue positron emission tomography (PET)/computer tomography (CT) or ${ }^{111}$ In-octreotide or $99 \mathrm{~m}$ Tc-tektrotyd scintigraphy) results were reported as tumor uptake in relation to liver uptake (none, <liver, =liver or >liver) and used as a surrogate for somatostatin receptor density. ${ }^{18} \mathrm{~F}$-flour-deoxy-glucose (FDG) PET/CT results were reported as tumor uptake present or not (positive or negative by qualitative assessment). Histological examination included chromogranin A (CgA) and synaptophysin staining, Ki-67\% in hot spots and tumor differentiation (poor, intermediate (c) 2019 Society for Endocrinology Published by Bioscientifica Ltd. Printed in Great Britain 
and well). Most of the centers have specific NET pathologists and in cases where differentiation was lacking in the original pathology report, a reclassification was done if sections were available. Plasma values of CgA, lactate dehydrogenase ( $\mathrm{LDH})$ and alkaline phosphatase (ALP) were determined shortly before the first PRRT cycle, and regularly afterward during and after the end of PRRT.

Patients were grouped according to Ki-67 index (21-54\% and $\geq 55 \%$ ) based on the Nordic NEC study and other reports (Sorbye et al. 2013, 2018, Garcia-Carbonero et al. 2016, Thang et al. 2018). Furthermore, patients were grouped by combined Ki-67\% and differentiation: Ki-67: 21-54\% and well-differentiated tumor (NET G3) vs Ki-67: 21-54\% and poorly differentiated tumor (NEC; Ki-67 21-54\%) vs Ki-67 $\geq 55 \%$ and poorly differentiated tumors (NEC; Ki-67 $\geq 55 \%$ ) (Milione et al. 2017).

Ethical committee approval was obtained in accordance with regional guidelines (either approval of the study or exempt of application due to the retrospective design). Regional ethics committees for participating centers are Rigshospitalet (Videnskabsetisk Komité, Region Hovedstaden) and Aarhus University Hospital (Videnskabsetisk Komité, Region Midt), Denmark; University Hospital Bonn (Ethikkommission an der Medizinischen Fakultät der RheinischenFriedrichWilhelms-Universität Bonn) and University Hospital Gießen and Marburg (Ethics Committee of the PhilippsUniversity Marburg, Medicine), Germany; HadassahHebrew University Medical Center (Hadassah-Hebrew University Medical Center Institutional Ethical Committee), Israel; European Institute of Oncology (Ethics Committee), Italy; Erasmus Medical Center (Medical Research and Ethics Committee, Rotterdam), The Netherlands; MSWiA Hospital Warsaw (Komisja Etyki i Nadzoru nad Badaniami na Ludziach), Poland; Uppsala University Hospital (Uppsala Regionala Etikprövningnämnden), Sweden; University Hospital Basel (Ethikkommission beider Basel), Switzerland; Churchill Hospital (Oxford Research and Ethics Committee) and Imperial College London (Regional Ethics Committee of Wales), United Kingdom. Patients gave informed consent before receiving PRRT.

\section{Treatment}

Patients received PRRT according to local guidelines at their respective institution. In general, treatment was given intravenously and consisted of a radioisotope (177Lutetium, ${ }^{90}$ Yttrium or ${ }^{111}$ Indium) conjugated with a somatostatin analogue (octreotide or octreotate). Patients were planned to a series of PRRT, typically consisting of four cycles each and separated by approximately 8 weeks. The intended cumulative activity was calculated by taking renal function and bone marrow irradiation into account. To reduce renal irradiation, patients were pretreated with an intravenous aminoacid solution. Planned PRRT cycles were discontinued in case of progression of disease or adverse effects limiting further cycles.

\section{Outcomes}

Response rate (RR) was defined as complete response (CR) or partial response (PR) according to the response evaluation criteria in solid tumors (RECIST 1.1) (Eisenhauer et al. 2009). Disease control rate (DCR) was defined as CR or PR in all patients or stable disease (SD) in patients with progressive disease (PD) at the start of PRRT. PFS was time from first cycle of PRRT to disease progression radiologically by RECIST 1.1 or clinically assessed by a physician (i.e. worsening of performance status due to NEN). If no progression was documented, date of death or date of last follow-up if alive was used. OS was time from first cycle of PRRT to death or date of last follow-up if still alive. Toxicity was reported as acute if occurring during PRRT and as long term if occurring after PRRT and within 1 year of PRRT. Toxicity was graded according to the Common Terminology Criteria for Adverse Events v.4, reporting grade 3-4 only.

\section{Statistics}

Continuous variables are reported as median and range. By means of Kaplan-Meier estimation, PFS and OS was calculated and reported as median with 95\% confidence interval (CI). Log-rank test was used to compare PFS and OS estimates between groups. Cox regression analysis was performed for PFS and OS with covariates: age, gender, performance status (PS), SRI tumor uptake, Ki-67 (dichotomized), primary tumor site, tumor morphology (well vs poorly differentiated, excluding the intermediate group due to few cases), plasma LDH and plasma ALP. Chi-square and Mann-Whitney $U$ tests were used to assess baseline variables associated with discontinuation of planned PRRT and PD as best response to PRRT. $P$ values $<0.05$ were considered statistically significant. All analyses were performed using SPSS statistics 25. (c) 2019 Society for Endocrinology Published by Bioscientifica Ltd. Printed in Great Britain 


\section{Results}

\section{Patients}

From August 1999 to May 2017, 149 patients with GEP NEN G3 received PRRT at 12 centers (Table 1). The primary tumor site was predominantly in the pancreas $(n=89)$ or unknown $(n=26)$. Other sites included the esophagus $(n=2)$, stomach $(n=4)$, gallbladder/common bile duct $(n=2)$, small bowel $(n=18)$, colon $(n=3)$, rectum $(n=3)$ and other abdominal sites $(n=2)$, here collectively referred to as GI $(n=34)$. All but two patients had metastatic disease. The median Ki-67 was 30\%, ranging from 21 to $100 \%$. Ki-67 21-54\% was found in the majority of patients ( $n=125)$ vs $\geq 55 \%(n=23)$, missing for one patient. Tumor morphology was equally distributed among poorly $(n=62)$ and well differentiated $(n=60)$ with only few cases of intermediate differentiation classification $(n=9)$. Seventeen of 20 patients (85\%) with Ki-67\% $\geq 55 \%$ vs 44 of 110 patients (40\%) with Ki-67 21-54\% had poorly differentiated tumor morphology. All patients with SRI showed tumor uptake, predominantly >liver uptake.

\section{Treatment}

At the start of PRRT, 104 patients (70\%) had radiologically progressive disease (determined by RECIST in 67 patients), which also was the main indication for PRRT (65\%) (Table 2). The median time from diagnosis to first PRRT was 8 months (range 0-174). PRRT was frequently given as second line $(n=62)$ or a later line of treatment $(n=57)$. Patients received a median of four cycles PRRT (range 1-15) with a median cumulative activity of 18 gigabecquerel (range 4-85). Radioisotopes ${ }^{177}$ Lutetium and/or ${ }^{90}$ Yttrium were used for PRRT in all patients other than a single patient who received ${ }^{111}$ Indium. Concurrent chemotherapy was used in six patients (4\%). Overall, 98 patients (66\%) completed their planned protocol of PRRT cycles, while 51 patients did not (Table 2). The main reasons for not completing the planned PRRT cycles were progressive disease $(n=19)$, clinical deterioration $(n=6)$ or toxicity $(n=6)$. Pre-treatment variables (Table 1$)$ associated with discontinuation of PPRT were poor tumor differentiation, unresected primary tumor and elevated plasma LDH $(P<0.05)$. Data on treatment after PRRT was available for 118 patients (79\%). Chemotherapy $(n=65)$ and somatostatin analogs (SSA) $(n=67)$ were frequently used, while surgery on the primary tumor or metastases $(n=8)$, liver embolization $(n=12)$ and external radiotherapy $(n=19)$ were less frequently used.
Table 1 Baseline characteristics of 149 patients with GEP NEN G3 receiving PRRT.

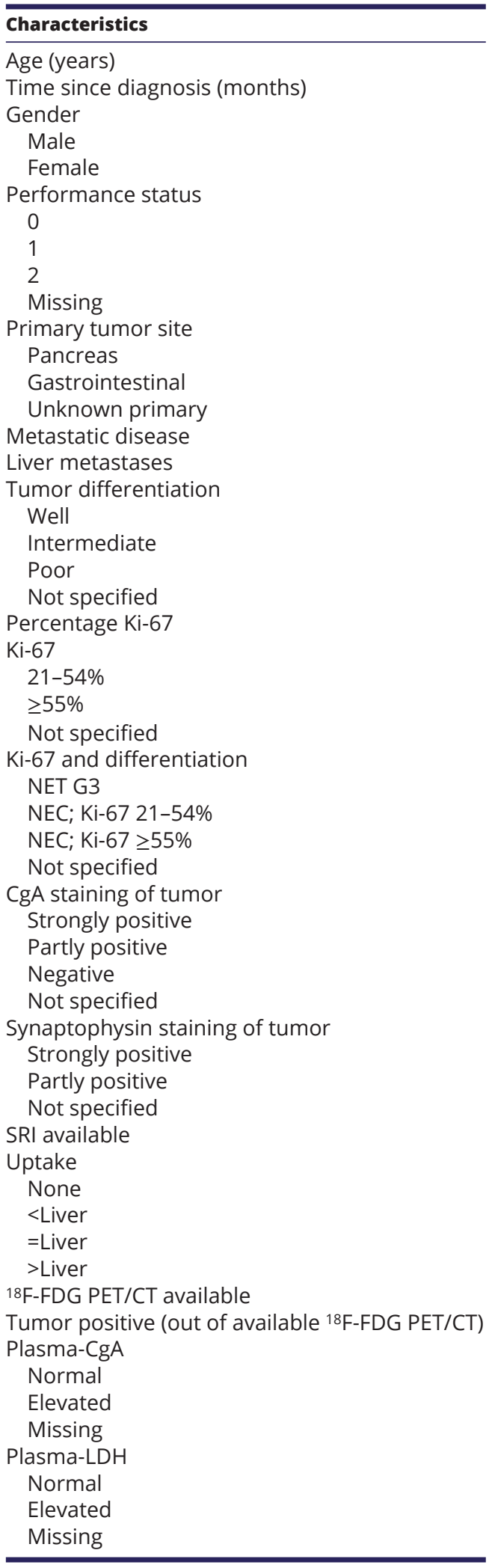

\begin{tabular}{c}
\hline Value \\
\hline $57(24-85)$ \\
$8(0-174)$
\end{tabular}

$76(51)$

$73(49)$

$74(50)$

$41(28)$

11 (7)

23 (15)

89 (60)

34 (23)

26 (17)

147 (99)

141 (95)

$60(40)$

9 (6)

62 (42)

18 (12)

$30(21-100)$

$125(84)$

23 (15)

1 (1)

58 (39)

44 (30)

$17(11)$

$30(20)$

$90(60)$

19 (13)

$9(6)$

$31(21)^{\mathrm{a}}$

105 (71)

11 (7)

33 (22)

$146(98)$

0

5 (3)

10 (7)

131 (88)

39 (26)

34 (87)

15 (10)

$83(56)$

51 (34)

76 (51)

35 (24)

$38(26)$

(Continued) 
Table 1 Continued.

\begin{tabular}{lc}
\hline Characteristics & Value \\
\hline Plasma-ALP & \\
Normal & $54(36)$ \\
Elevated & $67(45)$ \\
Missing & $28(19)$ \\
Number of prior lines of medical treatment & \\
0 & $30(20)$ \\
1 & $62(42)$ \\
2 & $31(21)$ \\
$>2$ & $26(18)$ \\
Prior treatment & \\
Primary tumor resected & $58(39)$ \\
Somatostatin analog & $74(50)^{\mathrm{b}}$ \\
Chemotherapy/targeted therapy & \\
In total & $88(59)$ \\
Cisplatin & $31(21)$ \\
Carboplatin & $26(17)$ \\
Etoposide & $46(31)$ \\
Capecitabine/5-fluorouracil & $38(26)$ \\
Temozolomide & $19(13)$ \\
Streptozotocin & $13(9)$ \\
Everolimus & $9(6)$ \\
Doxorubicin & $5(3)$ \\
Sunitinib & $4(3)$ \\
Oxaliplatin & $4(3)$ \\
Interferon & $2(1)$ \\
\hline
\end{tabular}

Age, time from diagnosis and Ki-67 are given as median with range; other variables are number with percentages.

aln 29 patients, CgA and synaptophysin staining results were not available; hereof 28 patients had SRI available that showed tumor uptake; bmissing values for seven patients.

${ }^{18}$ F-FDG PET/CT, Flour-Deoxy-Glucose positron emission tomography/ computer tomography; ALP, alkaline phosphatase; CgA, chromogranin A; GEP NEN G3, gastroenteropancreatic neuroendocrine neoplasm grade 3; $\mathrm{LDH}$, lactate dehydrogenase; PRRT, peptide receptor radionuclide therapy; SRI, somatostatin receptor imaging.

\section{Response and survival analysis}

Of 114 patients evaluable by RECIST, 1 (1\%) had CR, 47 (41\%) PR, 43 (38\%) SD and 23 (20\%) PD. An example of a PR is shown in Fig. 1. Disease control was seen in 79 patients (69\%) responding to PRRT. RR did not differ among subgroups, including differentiation (42 vs $43 \%$ for well and poorly differentiated, respectively) and Ki-67 index (42\% vs $43 \%$ for Ki-67 21-54\% and Ki-67 $\geq 55 \%$, respectively) (Table 3 ). RR was similar for patients treated with ${ }^{177} \mathrm{Lu}$ (40 of 86 patients) and ${ }^{90} \mathrm{Y}$ (5 of 16 patients) PRRT. Furthermore, we observed similar RR from the 12 centers (data not shown). Pre-treatment variables (Table 1) associated with PD were poor tumor differentiation, Ki-67 $\geq 55 \%$, and elevated plasma LDH $(P<0.05)$. Median follow-up was 23 months (range 0-210), and during follow-up 107 patients died. The cause of death was NEN in 91 of 94 cases with available data. The median PFS was 14 months (95\% CI 10.4-17.6) and median OS was
Table 2 Treatment details and toxicity of PRRT for 149 patients with GEP NEN G3.

\begin{tabular}{|c|c|}
\hline & Value \\
\hline \multicolumn{2}{|l|}{ Radiologically progressive disease at start of PRRT } \\
\hline Yes & $104(70)$ \\
\hline No & $35(24)$ \\
\hline Unknown & $10(7)$ \\
\hline \multicolumn{2}{|l|}{ Indication for PRRT } \\
\hline Progression of disease & $97(65)$ \\
\hline First line & $30(20)$ \\
\hline Side effects (not further specified) to other therapies & $6(4)$ \\
\hline Other & $16(11)$ \\
\hline \multicolumn{2}{|l|}{ Radioisotope } \\
\hline 177Lutetium & $101(68)$ \\
\hline 90Yttrium & $34(23)$ \\
\hline 177Lutetium + 90Yttrium & $12(8)$ \\
\hline${ }^{111}$ Indium & $1(1)$ \\
\hline Not specified & $1(1)$ \\
\hline Cumulative activity (gigabecquerel) & $18(4-85)$ \\
\hline Number of PRRT cycles & $4(1-15)$ \\
\hline Fulfilled planned number of cycles & $98(66)$ \\
\hline \multicolumn{2}{|l|}{ Discontinuation of PRRT } \\
\hline Disease progression & $19(13)$ \\
\hline Clinical deterioration & $6(4)$ \\
\hline Hematological side effects & $5(3)$ \\
\hline Renal side effects & $1(1)$ \\
\hline Lack of compliance & $1(1)$ \\
\hline Other & $17(11)$ \\
\hline Not specified & $2(1)$ \\
\hline \multicolumn{2}{|l|}{ Performance status after treatment } \\
\hline 0 & $74(50)$ \\
\hline 1 & $34(23)$ \\
\hline 2 & $11(7)$ \\
\hline 3 & $5(3)$ \\
\hline Not specified & $25(17)$ \\
\hline Absence of acute toxicity (grade 3-4) & $121(81)$ \\
\hline Patients with acute toxicitya & $19(13)$ \\
\hline Hematological, grade 3/grade 4, & $8 / 1$ \\
\hline Renal & $2 / 1$ \\
\hline Diarrhea & $0 / 2$ \\
\hline Nausea & $0 / 2$ \\
\hline Other, not specified & $14 / 1$ \\
\hline Unknown & $9(6)$ \\
\hline Absence of long-term toxicity (grade 3-4) & $101(68)$ \\
\hline Patients with long-term toxicitya & $19(13)$ \\
\hline Hematological, grade 3/grade 4, & $13 / 2$ \\
\hline Renal & $3 / 0$ \\
\hline Other, not specified & $3 / 3$ \\
\hline Unknown & $29(20)$ \\
\hline
\end{tabular}

Cumulative activity and number of PRRT cycles are given as median with range; other variables are number with percentage.

aMore than one toxicity may be present in a patient. GEP NEN G3, gastroenteropancreatic neuroendocrine neoplasm grade 3: PRRT, peptide receptor radionuclide therapy.

29 months (95\% CI 23.3-34.7) for all patients. Median PFS and OS were significantly longer for patients with a Ki-67 21-54\% $(P<0.001)$, well-differentiated tumor $(P<0.001)$, PS $<2(P<0.001)$, normal plasma levels of LDH $(P<0.001)$ and ALP $(P<0.001)$ (Figs 2 and 3$)$. PFS and OS 

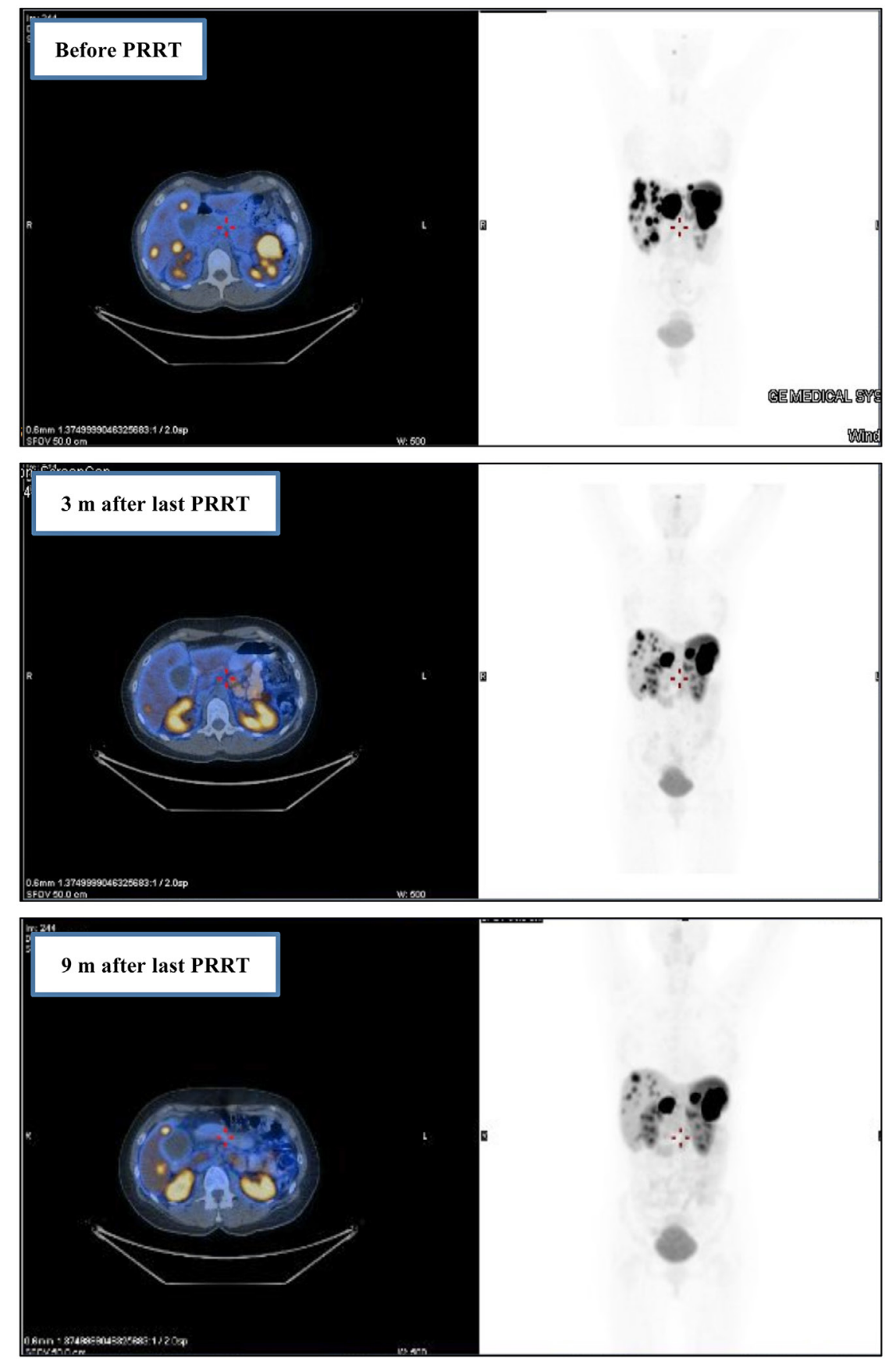

\section{Figure 1}

An example of PRRT in GEP NEN G3. Left-hand side: fused positron emission tomography (PET) and computer tomography (CT), transverse plane at kidney level. Right-hand side: whole-body maximum intensity projection, PET. A 47-year-old female with high-grade pancreatic neuroendocrine neoplasm (Ki67 of 70\%), metastatic to the liver. Received three cycles of peptide receptor radionuclide therapy with 177 Lu-DOTATATE. Follow-up with a durable partial response. PRRT, petide receptor radionuclide therapy; $\mathrm{m}$, months. A full colour version of this figure is available at https://doi.org/10.1530/ ERC-18-0424.

were independent of the amount of SRI tumor uptake, primary tumor site and line of treatment. In univariate analyses of PFS and OS, Ki-67 index, differentiation, PS as well as plasma LDH and ALP were statistically significant predictors (Table 4). In multivariate analysis $(n=75)$, PS, plasma LDH and ALP were statistically significant predictors for PFS and OS, and age was significant for PFS and differentiation for OS (Table 5). Excluding plasma LDH and ALP from the multivariate analysis resulted in 106 patients in the model; differentiation and
PS were statistically significant predictors for PFS and OS (data not shown).

\section{Toxicity}

Acute grade 3-4 toxicity occurred in 19 patients (13\%), most frequently hematological $(n=9)$ or renal $(n=3)$ (Table 2). In four patients, the acute hematological toxicity persisted beyond the time of PRRT and was thus included as long-term toxicity as well. Another 15 patients 
Table 3 PRRT response $(n=114)$ and outcomes $(n=149)$ in GEP NEN G3.

\begin{tabular}{|c|c|c|c|c|c|c|c|}
\hline & CR (\%) & PR (\%) & SD (\%) & PD (\%) & PFS (m) $(95 \% \mathrm{Cl})$ & $\mathbf{O S}(\mathrm{m})(95 \% \mathrm{Cl})$ & \\
\hline All patients & $1(1)$ & $47(41)$ & $43(38)$ & $23(20)$ & $14(10.4-17.6)$ & $29(23.3-34.7)$ & \\
\hline Performance status & & & & & & & a \\
\hline 0 & $1(2)$ & $21(36)$ & $26(45)$ & $10(17)$ & $16(11.0-21.0)$ & 39 (28.1-49.9) & \\
\hline 1 & 0 & $17(53)$ & $8(25)$ & $7(22)$ & $14(8.2-19.8)$ & $23(16.2-29.8)$ & \\
\hline 2 & 0 & $3(38)$ & $2(25)$ & $3(38)$ & $3(0-6.2)$ & $4(0-12.6)$ & \\
\hline \multicolumn{8}{|l|}{ SRI tumor uptake } \\
\hline$\leq$ Liver & $1(9)$ & $3(27)$ & $4(36)$ & $3(27)$ & $16(7.9-24.1)$ & $25(8.6-41.4)$ & \\
\hline >Liver & 0 & 44 (43) & $38(37)$ & $20(20)$ & $14(10.0-18.0)$ & $29(21.6-36.4)$ & \\
\hline \multicolumn{8}{|l|}{ Primary tumor site } \\
\hline Pancreas & 0 & $32(48)$ & $23(34)$ & $12(18)$ & $14(10.4-17.6)$ & $29(21.7-36.3)$ & \\
\hline Gastrointestinal & 0 & $11(42)$ & $9(35)$ & $6(23)$ & $10(0-21.2)$ & $31(7.5-54.5)$ & \\
\hline Unknown & $1(5)$ & $4(19)$ & $11(52)$ & $5(24)$ & $16(8.4-23.6)$ & $29(11.4-46.6)$ & \\
\hline Differentiation & & & & & & & a \\
\hline Well & 0 & $19(42)$ & $23(51)$ & $3(7)$ & $19(13.9-24.1)$ & $44(25.2-62.8)$ & \\
\hline Poor & $1(2)$ & $21(41)$ & $13(25)$ & $16(31)$ & $8(3.3-12.7)$ & $19(11.7-26.3)$ & \\
\hline Proliferation & & & & & & & a \\
\hline Ki-67 21-54\% & $1(1)$ & $41(41)$ & $41(41)$ & $16(16)$ & 16 (12.7-19.3) & $31(24.2-37.8)$ & \\
\hline Ki- $67 \geq 55 \%$ & 0 & $6(43)$ & $2(14)$ & $6(43)$ & $6(3.0-9.0)$ & $9(4.5-13.5)$ & \\
\hline $\begin{array}{l}\text { Differentiation and } \\
\text { proliferation }\end{array}$ & & & & & & & a \\
\hline NET G3 & 0 & $18(42)$ & $22(51)$ & $3(7)$ & $19(14.4-23.6)$ & $44(25.3-62.7)$ & \\
\hline NEC; Ki-67 21-54\% & $1(3)$ & $16(41)$ & $12(31)$ & $10(26)$ & $11(5.4-16.6)$ & $22(16.0-28.0)$ & \\
\hline NEC; Ki-67 $\geq 55 \%$ & 0 & $5(45)$ & $1(9)$ & $5(45)$ & $4(0.8-7.2)$ & $9(1.6-16.4)$ & \\
\hline
\end{tabular}

Response determined according to response evaluation criteria in solid tumors v 1.1. Statistically significant results are in bold text. aDenotes statistically significant difference in PFS and OS with $P$-values shown in Figs 2 and 3.

ALP, alkaline phosphatase; Cl, confidence interval; CR, complete response; GEP NEN G3, gastroenteropancreatic neuroendocrine neoplasm grade 3; LDH, lactate dehydrogenase; $\mathrm{m}$, months; NEC, neuroendocrine carcinoma; NET, neuroendocrine tumor; OS, overall survival; PD, progressive disease; PFS, progression-free survival; PR, partial response; PRRT, peptide receptor radionuclide therapy; SD, stable disease; SRI, somatostatin receptor imaging.

without any acute severe toxicity developed long-term hematological $(n=11)$, renal $(n=3)$ or not specified $(n=1)$ grade 3-4 toxicity. For first, second and later line of treatment, 5 (17\%), $16(26 \%)$ and $13(23 \%)$ patients had grade 3-4 toxicity, respectively. With ${ }^{177} \mathrm{Lu} 24$ (24\%), ${ }^{90} \mathrm{Y} 7(21 \%)$ and combined ${ }^{177} \mathrm{Lu} /{ }^{90} \mathrm{Y} 3(25 \%)$ patients had grade 3-4 toxicity, respectively. Renal grade 3-4 toxicity occurred in two patients $(6 \%)$ treated with ${ }^{90} \mathrm{Y}$ and four patients (4\%) treated with ${ }^{177} \mathrm{Lu}$.

\section{Discussion}

To the best of our knowledge, this is the largest study to assess the outcome after PRRT in patients with advanced high-grade GEP NEN. The majority of the patients had radiological progressive disease at the start of PRRT; RR was $42 \%$ and DCR was $69 \%$ for evaluable patients. A promising median PFS of 14 months and median OS of 29 months was found. Hematological or renal grade$3-4$ toxicity occurred in $17 \%$ of patients, not more than that observed for other patient groups given PRRT. These results suggest that PRRT can be effective and tolerable in high-grade GEP NEN patients.

C) 2019 Society for Endocrinology Published by Bioscientifica Ltd. Printed in Great Britain

\section{Comparison with standard treatment}

The current recommendations for first-line treatment of advanced GEP NEC are systemic platinum-based chemotherapy giving a RR of 30\%, PFS 4-5 months and OS 11 months (Sorbye et al. 2013, Yamaguchi et al. 2014, Heetfeld et al. 2015, Walter et al. 2017). Secondline treatment for NEC is usually of short benefit with an estimated PFS of 3-4 months (Welin et al. 2011, Hentic et al. 2012, Olsen et al. 2012, 2014, Hadoux et al. 2015, Walter et al. 2017). The Nordic NEC study showed a poorer RR to platinum-based chemotherapy in patients with Ki-67 $<55 \%$ (RR: $15 \%$ ) compared to patients with a Ki-67 $\geq 55 \%$ (RR: 42\%) (Sorbye et al. 2013). Data for advanced NET G3 are generally scarce; however, RR to platinum-based chemotherapy is low (0-17\%) with a short PFS (2.4 months) (Sorbye et al. 2018). Median survival is reported to be more than 40 months but as data are presented as a mixture of stages, results are difficult to interpret (Velayoudom-Cephise et al. 2013, Heetfeld et al. 2015, Hijioka et al. 2017, Sorbye et al. 2018). In a high-grade GEP-NEN population of 136 patients, median survival from time of first diagnosis was best for NET G3 (43.6 months), intermediate for NEC with a Ki-67 

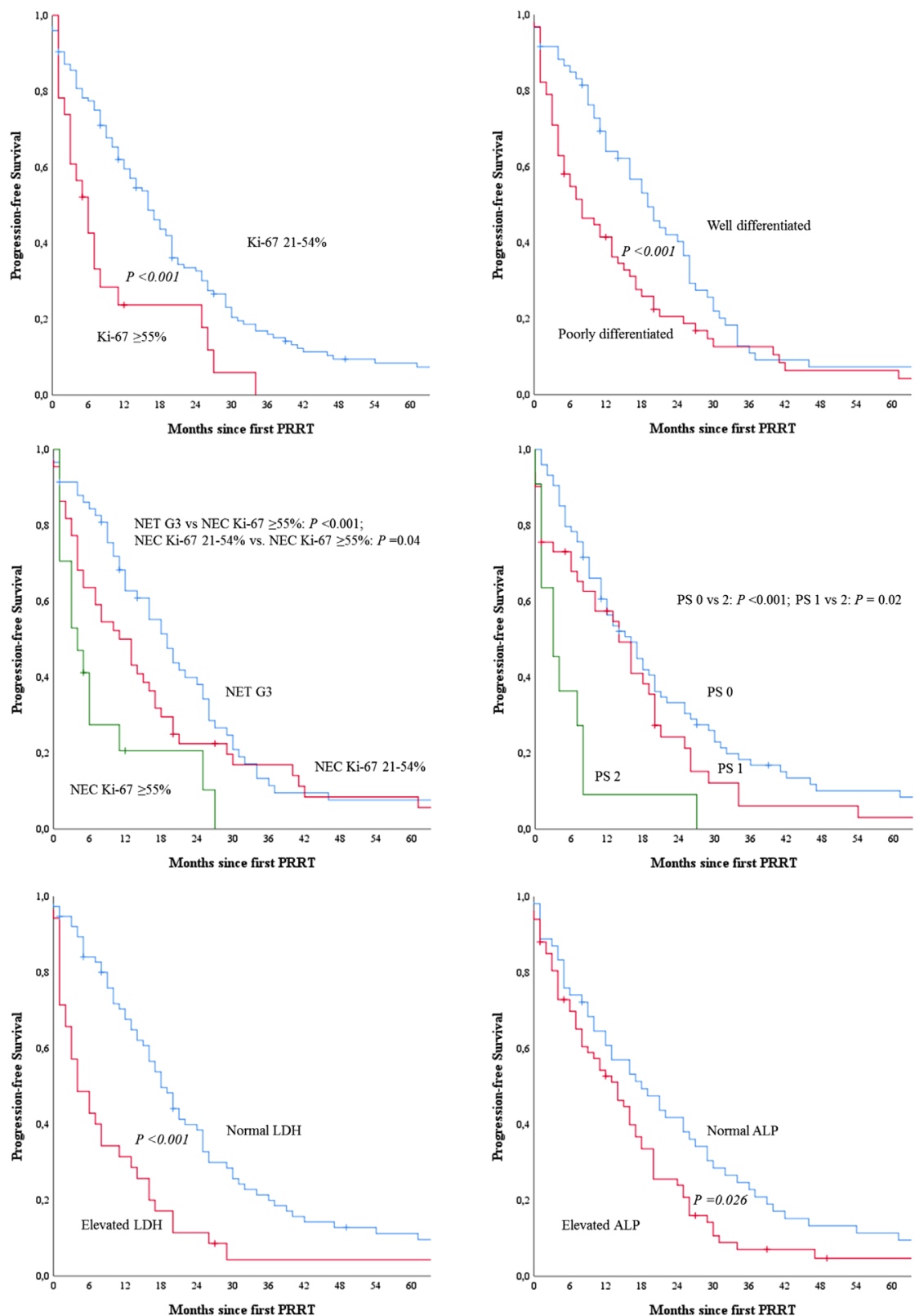

Figure 2

Kaplan-Meier curves of PFS for 149 patients with GEP NEN G3 treated with PRRT. Stratification by Ki-67 index $(n=148)$, differentiation $(n=122)$, performance status (PS) $(n=126)$, combined Ki-67 index and differentiation $(n=119), \mathrm{LDH}(n=111)$ and $\operatorname{ALP}(n=121)$, respectively. PFS, progression free-survival; GEP NEN G3, gastroenteropancreatic neuroendocrine neoplasm grade 3; PRRT, peptide receptor radionuclide therapy. A full colour version of this figure is available at https://doi. org/10.1530/ERC-18-0424.
21-54\% (24.5 months) and 5.3 months for NEC cases with a Ki-67 $\geq 55 \%$ (Milione et al. 2017). A combination of capecitabine and temozolomide has been suggested for patients with well-differentiated tumor morphology and a Ki-67 21-54\%, but data are scarce (Heetfeld et al. 2015, Garcia-Carbonero et al. 2016, Sorbye et al. 2018). In our cohort, half the patients were treated with SSA either before and/or after PRRT. SSA is not recommended for high-grade NEN, but may be explained by the selection of patients with a positive SRI or use of SSA after PRRT in general.

Cross-trial comparisons are difficult as well as evaluation of the benefit of PRRT without a control arm.
However, a RR of $42 \%$ and DCR of $69 \%$ indicate that PRRT has an effect in our cohort. No differences in RR were observed in subgroups according to both well vs

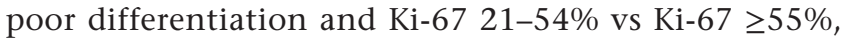
as RR was approximately $40 \%$ in all subgroups. It may be that the efficacy of PRRT mediated by radiation is less sensitive to the degree of differentiation and rate of proliferation as long as the somatostatin receptor target is present on the tumor cells. The benefit of platinumbased chemotherapy seems to be more dependent on a high degree of proliferation, as evident in the Nordic NEC study (Sorbye et al. 2013). As most of our patients had radiologically progressive disease at the start of PRRT, 

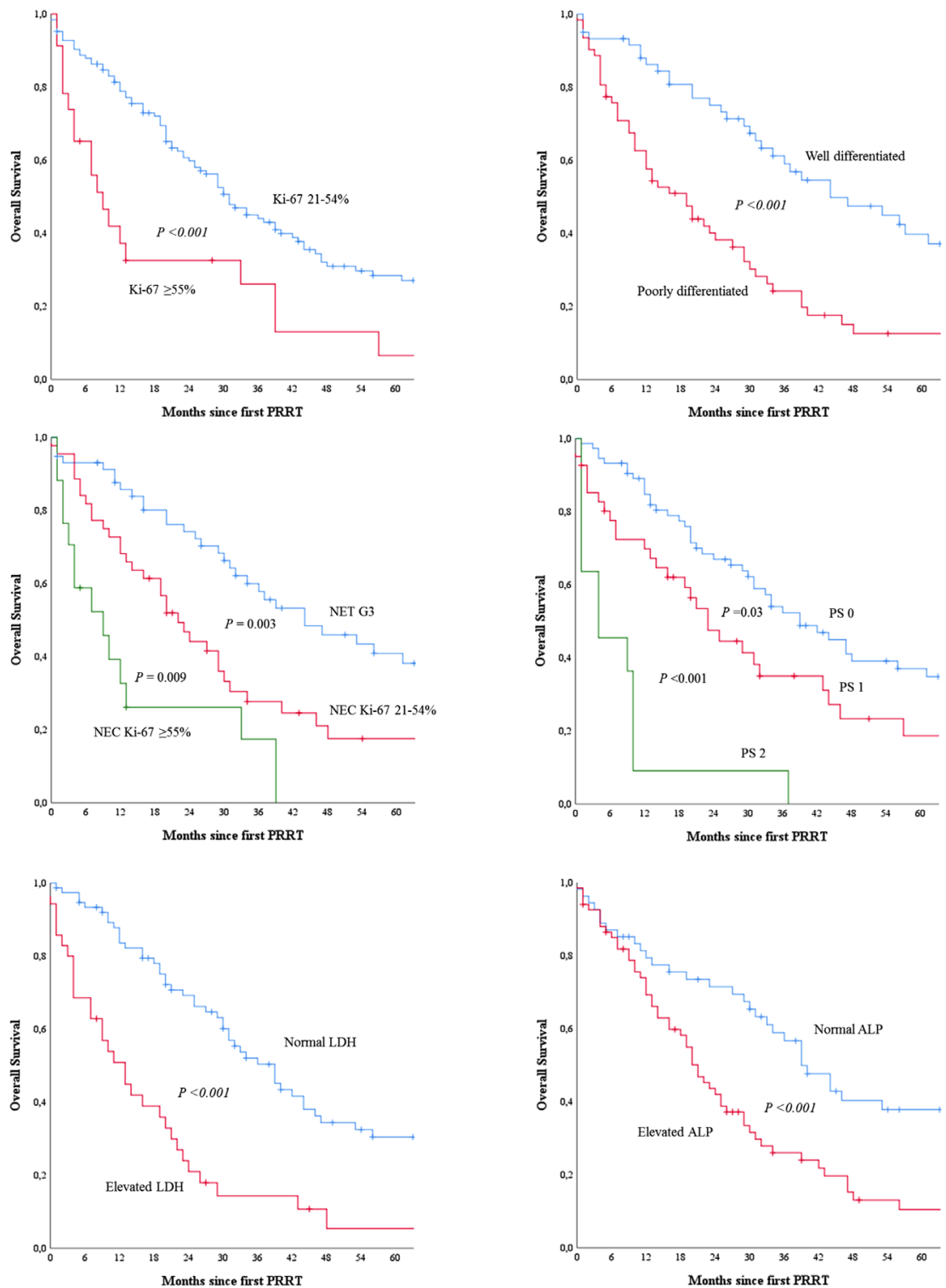

Figure 3

Kaplan-Meier analysis of OS for 149 patients with GEP NEN G3 treated with PRRT. Stratification by Ki-67 index ( $(n=148)$, differentiation $(n=122)$, performance status (PS) $(n=126)$, combined Ki-67 index and differentiation $(n=119), \mathrm{LDH}(n=111)$ and ALP ( $n=121)$, respectively. OS, overall survival; GEP NEN G3, gastroenteropancreatic

neuroendocrine neoplasm grade 3; PRRT, peptide receptor radionuclide therapy. A full colour version of this figure is available at https://doi.org/10.1530/ ERC-18-0424. a PFS of 14 months indicates that PRRT seems to benefit many patients. Interestingly, no differences in RR, PFS and OS were evident in our cohort in regard to the line of treatment. Differentiation, Ki-67, PS, LDH and ALP were all significantly correlated to OS, as shown in previous studies (Sorbye et al. 2013, Lamarca et al. 2017). However, the true benefit of PRRT for PFS and especially OS is not possible to decide without a prospective randomized trial, which will be difficult to perform in such a rare disease. Since PRRT would seem most likely as a therapeutic option in NET G3, a prospective randomized trial comparing PRRT vs chemotherapy (temozolomide/capecitabine) in this population (or NEN G3 with a Ki67 <55\%) is essential. Data are awaited to clarify whether concurrent chemotherapy to PRRT should be considered (ClinicalTrials.gov: NCT02736448).

\section{Comparison with previous PRRT data in NEN G3 and classification}

Three single-center retrospective studies recently reported the outcome of PRRT in NEN with a high Ki-67 and SRI tumor uptake >liver. An Australian study (Thang et al. 2018) assessed 28 patients with NEN and Ki-67 >20\% (median Ki-67: 32.5\%). The majority received PRRT with concurrent chemotherapy. The RR was 35\%, PFS 9 months and OS 19 months for all patients. According to Ki-67 index PFS (12 vs 4 months) and OS (46 vs 7 months) differed for Ki-67 $\leq 55 \%$ and Ki-67 $>55 \%$. 
Table 4 Univariate analyses of predictors for PFS and OS in 149 GEP NEN G3 patients treated with PRRT.

\begin{tabular}{l}
\hline Covariate \\
\hline Age \\
Male \\
Performance status 0 \\
Performance status 1 \\
Performance status 2 \\
SRI $\leq$ liver \\
Primary tumor site (unknown primary) \\
Gastrointestinal \\
Pancreas \\
Poorly differentiated \\
Ki-67 $\geq 55 \%$ \\
Differentiation and proliferation (NET G3) \\
NEC; Ki-67 21-54\% \\
NEC; Ki-67 $\geq 55 \%$ \\
Line of treatment (first line) \\
Second line \\
Later line \\
Elevated plasma-LDH \\
Elevated plasma-ALP
\end{tabular}

\begin{tabular}{l}
\hline PFS \\
\hline Hazard ratio $(95 \% \mathrm{Cl})$ \\
\hline $1.00(0.99-1.02)$ \\
$0.96(0.68-1.34)$ \\
1 \\
$1.36(0.91-2.04)$ \\
$\mathbf{3} .53(\mathbf{1 . 8 3}-6.83)$ \\
$1.17(0.67-2.04)$ \\
1 \\
$1.13(0.65-1.95)$ \\
$1.29(0.80-2.07)$ \\
$\mathbf{1 . 6 2}(\mathbf{1 . 1 1 - 2 . 3 6 )}$ \\
$\mathbf{2 . 1 5}(\mathbf{1 . 3 4}-\mathbf{3 . 4 7})$ \\
1 \\
$1.38(0.91-2.07)$ \\
$\mathbf{2 . 8 1}(\mathbf{1 . 5 5 - 5 . 1 1 )}$ \\
1 \\
$1.08(0.69-1.69)$ \\
$0.79(0.50-1.24)$ \\
$\mathbf{2 . 3 5}(\mathbf{1 . 5 4 - 3 . 5 9 )}$ \\
$\mathbf{1 . 5 3}(\mathbf{1 . 0 4 - 2 . 2 4 )}$
\end{tabular}

\begin{tabular}{c}
\hline P-Value \\
\hline 0.84 \\
0.79 \\
0.14 \\
$<0.001$ \\
0.59 \\
0.67 \\
0.30 \\
$\mathbf{0 . 0 1}$ \\
$\mathbf{0 . 0 0 2}$ \\
0.13 \\
$\mathbf{0 . 0 0 1}$ \\
0.73 \\
0.31 \\
$<0.001$ \\
$\mathbf{0 . 0 3}$ \\
\hline
\end{tabular}

\begin{tabular}{|c|c|}
\hline \multicolumn{2}{|l|}{ os } \\
\hline Hazard ratio $(95 \% \mathrm{Cl})$ & $P$-Value \\
\hline $1.01(0.99-1.03)$ & 0.20 \\
\hline $0.78(0.53-1.1)$ & 0.19 \\
\hline 1 & \\
\hline $1.65(1.04-2.63)$ & 0.04 \\
\hline $6.84(3.40-13.76)$ & $<0.001$ \\
\hline $0.79(0.40-1.57)$ & 0.50 \\
\hline 1 & \\
\hline $0.75(0.41-1.39)$ & 0.36 \\
\hline $0.83(0.50-1.37)$ & 0.46 \\
\hline $2.55(1.62-4.02)$ & $<0.001$ \\
\hline $2.48(1.51-4.06)$ & $<0.001$ \\
\hline 1 & \\
\hline $2.06(1.26-3.39)$ & 0.004 \\
\hline $4.77(2.51-9.06)$ & $<0.001$ \\
\hline 1 & \\
\hline $1.04(0.63-1.71)$ & 0.87 \\
\hline $0.86(0.52-1.42)$ & 0.55 \\
\hline $3.14(1.96-5.02)$ & $<0.001$ \\
\hline $2.21(1.42-3.45)$ & $<0.001$ \\
\hline
\end{tabular}

Statistically significant results are in bold text.

ALP, alkaline phosphatase; $\mathrm{Cl}$, confidence interval; GEP NEN G3, gastroenteropancreatic neuroendocrine neoplasm grade 3; LDH, lactate dehydrogenase; NEC, neuroendocrine carcinoma; NET G3, neuroendocrine tumor grade 3; OS, overall survival; PFS, progression free-survival; PRRT, peptide receptor radionuclide therapy; SRI, somatostatin receptor imaging.

A German study (Zhang et al. 2018) assessed 69 patients with GEP NEN and Ki-67 index >20\% (median Ki-67, $30 \%)$. In their study, approximately one-third received concurrent chemotherapy - the effect hereof was reported as uncertain. The RR was 31\%, DCR 78\%, PFS 10 months and OS 20 months. According to Ki-67 index PFS (11 vs 4 months) and OS (22 vs 7 months) differed for Ki-67 $\leq 55 \%$ and Ki-67 >55\%. An Italian study (Nicolini et al. 2018) assessed 33 patients with GEP NEN and Ki-67 index of 15-70\% (median Ki-67: 25\%). The RR was 6\%, PFS 23 months and OS 52.9 months. Overall, in our study we found similar results: PFS (16 vs 6 months) and OS (31 vs 9 months) differed significantly in patients with Ki-67 $<55 \%$ vs Ki-67 $\geq 55 \%$.

In general, the likelihood of somatostatin receptor expression on neuroendocrine cells decreases with increasing grade of tumor, whereas the opposite applies for FDG uptake (Binderup et al. 2010, Hicks et al. 2017). NET G3 seems to have a positive SRI uptake in $70 \%$ of cases, whereas for NEC the figure is more likely 30\% (Sorbye et al. 2013, 2018, Velayoudom-Cephise et al. 2013, Heetfeld et al. 2015, Raj et al. 2017). Preliminary studies have also shown the effectiveness of PRRT in patients with a more aggressive grade NEN with ${ }^{18} \mathrm{~F}-\mathrm{FDG}$ and SRI uptake (Kashyap et al. 2015). Patients with concordant ${ }^{18}$ F-FDG and SRI-avid lesions may be more radiosensitive by having a high proliferative fraction. Few of the patients in our cohort had ${ }^{18}$ F-FDG PET/CT data available limiting further analysis.

As previously reported (Basturk et al. 2015), the grading of NEN according to Ki-67 may be optimized by further sub-classification of patients with Ki-67 >20\%. In the current study of patients graded as NEN G3 based on Ki-67, nearly half the patients had well-differentiated tumor morphology. The majority of patients with welldifferentiated tumors also had Ki-67 21-54\%. There was a marked difference in outcomes in our cohort when comparing subgroups based on tumor morphology: PFS (19 vs 8 months) and OS (44 vs 19 months) differed significantly comparing well-differentiated vs poorly differentiated neoplasms.

\section{Toxicity}

In our study, 26 patients (17\%) had either acute or longterm grade 3-4 renal or hematological toxicity. This is similar to that reported in other larger retrospective analysis of patient groups given PRRT (Kwekkeboom et al. 2008, Imhof et al. 2011), although in NETTER-1, no evidence of renal adverse effects was observed in patients treated with ${ }^{177} \mathrm{Lu}$ (Strosberg et al. 2017). We observed renal toxicity both in patients treated with ${ }^{90} \mathrm{Y}$ and ${ }^{177} \mathrm{Lu}$. https://erc.bioscientifica.com

https://doi.org/10.1530/ERC-18-0424 (c) 2019 Society for Endocrinology Published by Bioscientifica Ltd. Printed in Great Britain 
Table 5 Multivariate Cox regression analysis of predictors for PFS and OS in 75 GEP NEN G3 patients treated with PRRT.

\begin{tabular}{l}
\hline Covariate \\
\hline Age \\
Male \\
Performance status 0 \\
Performance status 1 \\
Performance status 2 \\
SRI $\leq$ liver \\
Primary tumor site (unknown primary) \\
Gastrointestinal \\
Pancreas \\
Poorly differentiated \\
Ki-67 $\geq 55 \%$ \\
Line of treatment (first line) \\
Second line \\
Later line \\
Elevated plasma-LDH \\
Elevated plasma-ALP \\
\hline
\end{tabular}

\begin{tabular}{ll}
\hline \multicolumn{1}{c}{ PFS } \\
\hline Hazard ratio $(95 \% \mathrm{Cl})$ \\
\hline $\mathbf{0 . 9 8}(\mathbf{0 . 9 5 - 1 . 0 0 )}$ \\
$1.53(0.85-2.74)$ \\
1 \\
$\mathbf{2 . 5 7}(\mathbf{1 . 3 3 - 4 . 9 3 )}$ \\
$3.42(0.90-13.06)$ \\
$0.72(0.13-4.03)$ \\
1 \\
$0.80(0.32-2.02)$ \\
$0.66(0.28-1.57)$ \\
$1.69(0.88-3.23)$ \\
$1.11(0.51-2.42)$ \\
1 \\
$0.76(0.38-1.54)$ \\
$1.04(0.48-2.27)$ \\
$\mathbf{2 . 6 6}(\mathbf{1 . 2 9 - 5 . 4 9 )}$ \\
$\mathbf{2 . 2 4}(\mathbf{1 . 2 2 - 4 . 0 9 )}$ \\
\hline
\end{tabular}

\begin{tabular}{l}
$P$-Value \\
\hline $\mathbf{0 . 0 4 5}$ \\
0.16 \\
\\
$\mathbf{0 . 0 0 5}$ \\
0.07 \\
0.70 \\
0.64 \\
0.35 \\
0.11 \\
0.80 \\
0.46 \\
0.91 \\
$\mathbf{0 . 0 0 8}$ \\
$\mathbf{0 . 0 0 9}$ \\
\hline
\end{tabular}

\begin{tabular}{|c|c|}
\hline \multicolumn{2}{|l|}{ os } \\
\hline Hazard ratio $(95 \% \mathrm{Cl})$ & $P$-Value \\
\hline $0.99(0.96-1.02)$ & 0.42 \\
\hline $1.05(0.53-2.10)$ & 0.89 \\
\hline 1 & \\
\hline 2.35 (1.13-4.89) & 0.02 \\
\hline $4.20(0.98-18.01)$ & 0.05 \\
\hline $0.43(0.04-4.33)$ & 0.47 \\
\hline 1 & \\
\hline $0.78(0.26-2.37)$ & 0.66 \\
\hline $0.46(0.18-1.22)$ & 0.12 \\
\hline $2.92(1.31-6.50)$ & 0.009 \\
\hline $1.97(0.83-4.66)$ & 0.13 \\
\hline 1 & \\
\hline $1.55(0.70-3.43)$ & 0.28 \\
\hline $1.77(0.67-4.65)$ & 0.25 \\
\hline $2.61(1.16-5.90)$ & 0.02 \\
\hline 2.79 (1.42-5.49) & 0.003 \\
\hline
\end{tabular}

Due to missing values for one or more of the covariates, 74 patients were not included in the model. Statistically significant results are in bold text. ALP, alkaline phosphatase; Cl, confidence interval; GEP NEN G3, gastroenteropancreatic neuroendocrine neoplasm grade 3; LDH, lactate dehydrogenase; OS, overall survival; PFS, progression free-survival; PRRT, peptide receptor radionuclide therapy; SRI, somatostatin receptor imaging.

Furthermore, we found similar frequency of toxicity for patients receiving PRRT as first line vs later line of treatment.

\section{Limitations}

High-grade GEP NEN patients treated with PRRT are probably highly selected on factors as being positive on SRI imaging and having a rather low median Ki-67 compared to the NEN G3 group as a whole. RR, PFS and OS should be interpreted carefully in light of the retrospective design of the study. However, most of our patients were classified as having radiological progression of disease at the start of PRRT, and approximately half were based on RECIST. The rate of side effects of PRRT in our analysis was in line with that previously reported for PRRT, but toxicity reports in a retrospective study must be interpreted cautiously. Pathologist reports were mainly from NET expert centers and reclassification was done in reports with missing data when sections were available. Though, a general problem is that the distinction between well and poor differentiation is not standardized (Tang et al. 2016) and at present it is only determined based on tumor morphology (Kloppel et al. 2017). Future studies possibly adding molecular data on DAXX, ATRX (loss of expression in well-differentiated pancreatic tumors) and Rb1, KRAS and p53 (expressed in poorly differentiated tumors), could assist further to classify these tumors (Sorbye et al. 2018).

\section{Conclusion}

This large retrospective multicenter study is at present the most comprehensive report on which to base treatment decisions regarding the use of PRRT in high-grade GEP NEN. It shows promising RR, DCR, PFS and OS and acceptable toxicity after PRRT in patients with mainly progressive disease. This suggests that PRRT is active and potentially effective in patients with GEP NEN G3. Awaiting further data, PRRT may therefore be a treatment option for GEP NEN G3 patients.

\section{Declaration of interest}

E A C has received paid travel to meetings by Novartis and Ipsen. $\mathrm{H}$ A has received a grant from Novartis and honorarium from Ipsen and Novartis for oral presentations. A R has received honoraria for presentations and attendance at advisory board meetings from Novartis and Ipsen. A F has received funding from Ipsen, Novartis, AAA and SIRTeX. $U$ K has received funding from 'Internationaliseringspuljen', Institute for Clinical Medicine, University of Copenhagen, Denmark to perform research in NEC.

\section{Funding}

This research did not receive any specific grant from any funding agency in the public, commercial or not-for-profit sector.

\section{Acknowledgements}

The authors are thankful for comments provided by Dr David J Gross (Neuroendocrine Tumor Unit, Endocrinology and Metabolism Service, at Hadassah) and thank Dr Ophra Maimon (Oncology Department and Radiation Therapy Unit at Hadassah) for assistance in collecting patient
2019 Society for Endocrinology Published by Bioscientifica Ltd. Printed in Great Britain 
data from Jerusalem. Thanks to $\mathrm{Dr}$ Ashley Grossman for assisting in collecting patient data from Oxford and linguistic advice for the paper.

\section{References}

Basturk O, Yang Z, Tang LH, Hruban RH, Adsay V, McCall CM, Krasinskas AM, Jang KT, Frankel WL, Balci S, et al. 2015 The highgrade (WHO G3) pancreatic neuroendocrine tumor category is morphologically and biologically heterogenous and includes both well differentiated and poorly differentiated neoplasms. American Journal of Surgical Pathology 39 683-690. (https://doi.org/10.1097/ PAS.0000000000000408)

Binderup T, Knigge U, Loft A, Mortensen J, Pfeifer A, Federspiel B, Hansen CP, Hojgaard L \& Kjaer A 2010 Functional imaging of neuroendocrine tumors: a head-to-head comparison of somatostatin receptor scintigraphy, 123I-MIBG scintigraphy, and 18F-FDG PET. Journal of Nuclear Medicine 51 704-712. (https://doi.org/10.2967/ jnumed.109.069765)

Bodei L, Cremonesi M, Grana CM, Fazio N, Iodice S, Baio SM, Bartolomei M, Lombardo D, Ferrari ME, Sansovini M, et al. 2011 Peptide receptor radionuclide therapy with (1)(7)(7)Lu-DOTATATE: the IEO phase I-II study. European Journal of Nuclear Medicine and Molecular Imaging 38 2125-2135. (https://doi.org/10.1007/s00259011-1902-1)

Bosman FT, Carneiro F, Hruban RH \& Theise ND 2010 WHO Classification of Tumours of the Digestive System. Lyon: International Agency for Research on Cancer.

Dasari A, Mehta K, Byers LA, Sorbye H \& Yao JC 2018 Comparative study of lung and extrapulmonary poorly differentiated neuroendocrine carcinomas: a SEER database analysis of 162,983 cases. Cancer 124 807-815. (https://doi.org/10.1002/cncr.31124)

Eisenhauer EA, Therasse P, Bogaerts J, Schwartz LH, Sargent D, Ford R, Dancey J, Arbuck S, Gwyther S, Mooney M, et al. 2009 New response evaluation criteria in solid tumours: revised RECIST guideline (version 1.1). European Journal of Cancer 45 228-247. (https://doi. org/10.1016/j.ejca.2008.10.026)

Garcia-Carbonero R, Sorbye H, Baudin E, Raymond E, Wiedenmann B, Niederle B, Sedlackova E, Toumpanakis C, Anlauf M, Cwikla JB, et al. 2016 ENETS consensus guidelines for high-grade gastroenteropancreatic neuroendocrine tumors and neuroendocrine carcinomas. Neuroendocrinology 103 186-194. (https://doi. org/10.1159/000443172)

Hadoux J, Malka D, Planchard D, Scoazec JY, Caramella C, Guigay J, Boige V, Leboulleux S, Burtin P, Berdelou A, et al. 2015 Post-first-line FOLFOX chemotherapy for grade 3 neuroendocrine carcinoma. Endocrine-Related Cancer 22 289-298. (https://doi.org/10.1530/ERC15-0075)

Heetfeld M, Chougnet CN, Olsen IH, Rinke A, Borbath I, Crespo G, Barriuso J, Pavel M, O'Toole D, Walter T, et al. 2015 Characteristics and treatment of patients with G3 gastroenteropancreatic neuroendocrine neoplasms. Endocrine-Related Cancer 22 657-664. (https://doi.org/10.1530/ERC-15-0119)

Hentic O, Hammel P, Couvelard A, Rebours V, Zappa M, Palazzo M, Maire F, Goujon G, Gillet A, Levy P, et al. 2012 FOLFIRI regimen: an effective second-line chemotherapy after failure of etoposideplatinum combination in patients with neuroendocrine carcinomas grade 3. Endocrine-Related Cancer 19 751-757. (https://doi. org/10.1530/ERC-12-0002)

Hicks RJ, Kwekkeboom DJ, Krenning E, Bodei L, Grozinsky-Glasberg S, Arnold R, Borbath I, Cwikla J, Toumpanakis C, Kaltsas G, et al. 2017 ENETS consensus guidelines for the standards of care in neuroendocrine neoplasia: peptide receptor radionuclide therapy with radiolabeled somatostatin analogues. Neuroendocrinology 105 295-309. (https://doi.org/10.1159/000475526)
Hijioka S, Hosoda W, Matsuo K, Ueno M, Furukawa M, Yoshitomi H, Kobayashi N, Ikeda M, Ito T, Nakamori S, et al. 2017 Rb loss and KRAS mutation are predictors of the response to platinum-based chemotherapy in pancreatic neuroendocrine neoplasm with grade 3 : a Japanese multicenter pancreatic NEN-G3 study. Clinical Cancer Research 23 4625-4632. (https://doi.org/10.1158/1078-0432.CCR-163135)

Ilett EE, Langer SW, Olsen IH, Federspiel B, Kjaer A \& Knigge U 2015 Neuroendocrine carcinomas of the gastroenteropancreatic system: a comprehensive review. Diagnostics 5 119-176. (https://doi. org/10.3390/diagnostics5020119)

Imhof A, Brunner P, Marincek N, Briel M, Schindler C, Rasch H, Macke HR, Rochlitz C, Muller-Brand J \& Walter MA 2011 Response, survival, and long-term toxicity after therapy with the radiolabeled somatostatin analogue [90Y-DOTA]-TOC in metastasized neuroendocrine cancers. Journal of Clinical Oncology 29 2416-2423. (https://doi.org/10.1200/JCO.2010.33.7873)

Kashyap R, Hofman MS, Michael M, Kong G, Akhurst T, Eu P, Zannino D \& Hicks RJ 2015 Favourable outcomes of (177) Lu-octreotate peptide receptor chemoradionuclide therapy in patients with FDG-avid neuroendocrine tumours. European Journal of Nuclear Medicine and Molecular Imaging 42 176-185. (https://doi. org/10.1007/s00259-014-2906-4)

Kloppel G, Couvelard A, Hruban RH, Klimstra DS, Komminoth P, Osamura RY, Perren A \& Rindi G 2017 Neoplasms of the neuroendocrine pancreas. In WHO Classification of Tumours of Endocrine Organs, 4th ed., pp 211-214. Eds RV Lloyd, RY Osamura, G Klöppel \& J Rosai. Lyon, France: IARC Press.

Konukiewitz B, Schlitter AM, Jesinghaus M, Pfister D, Steiger K, Segler A, Agaimy A, Sipos B, Zamboni G, Weichert W, et al. 2017 Somatostatin receptor expression related to TP53 and RB1 alterations in pancreatic and extrapancreatic neuroendocrine neoplasms with a Ki67-index above 20. Modern Pathology 30 587-598. (https://doi.org/10.1038/ modpathol.2016.217)

Kwekkeboom DJ, de Herder WW, Kam BL, van Eijck CH, van Essen M, Kooij PP, Feelders RA, van Aken MO \& Krenning EP 2008 Treatment with the radiolabeled somatostatin analog [177 Lu-DOTA 0,Tyr3] octreotate: toxicity, efficacy, and survival. Journal of Clinical Oncology 26 2124-2130. (https://doi.org/10.1200/JCO.2007.15.2553)

Lamarca A, Walter T, Pavel M, Borbath I, Freis P, Nunez B, Childs A, McNamara MG, Hubner RA, Garcia-Carbonero R, et al. 2017 Design and validation of the GI-NEC score to prognosticate overall survival in patients with high-grade gastrointestinal neuroendocrine carcinomas. Journal of the National Cancer Institute 109 djw277. (https://doi.org/10.1093/jnci/djw277)

Milione M, Maisonneuve P, Spada F, Pellegrinelli A, Spaggiari P, Albarello L, Pisa E, Barberis M, Vanoli A, Buzzoni R, et al. 2017 The clinicopathologic heterogeneity of grade 3 gastroenteropancreatic neuroendocrine neoplasms: morphological differentiation and proliferation identify different prognostic categories. Neuroendocrinology 104 85-93. (https://doi. org/10.1159/000445165)

Nicolini S, Severi S, Ianniello A, Sansovini M, Ambrosetti A, Bongiovanni A, Scarpi E, Di Mauro F, Rossi A, Matteucci F, et al. 2018 Investigation of receptor radionuclide therapy with (177) Lu-DOTATATE in patients with GEP-NEN and a high Ki-67 proliferation index. European Journal of Nuclear Medicine and Molecular Imaging 45 923-930. (https://doi.org/10.1007/s00259-017-3925-8)

Olsen IH, Sorensen JB, Federspiel B, Kjaer A, Hansen CP, Knigge U \& Langer SW 2012 Temozolomide as second or third line treatment of patients with neuroendocrine carcinomas. Scientific World Journal 2012 170496. (https://doi.org/10.1100/2012/170496)

Olsen IH, Knigge U, Federspiel B, Hansen CP, Skov A, Kjaer A \& Langer SW 2014 Topotecan monotherapy in heavily pretreated patients with progressive advanced stage neuroendocrine (c) 2019 Society for Endocrinology Published by Bioscientifica Ltd. Printed in Great Britain 
carcinomas. Journal of Cancer 5 628-632. (https://doi.org/10.7150/ jca.9409)

Pfeifer AK, Gregersen T, Gronbaek H, Hansen CP, Muller-Brand J, Herskind Bruun K, Krogh K, Kjaer A \& Knigge U 2011 Peptide receptor radionuclide therapy with Y-DOTATOC and (177) Lu-DOTATOC in advanced neuroendocrine tumors: results from a Danish cohort treated in Switzerland. Neuroendocrinology 93 189-196. (https://doi.org/10.1159/000324096)

Raj N, Valentino E, Capanu M, Tang LH, Basturk O, Untch BR, Allen PJ Klimstra DS \& Reidy-Lagunes D 2017 Treatment response and outcomes of grade 3 pancreatic neuroendocrine neoplasms based on morphology: well differentiated versus poorly differentiated. Pancreas 46 296-301. (https://doi.org/10.1097/MPA.0000000000000735)

Romer A, Seiler D, Marincek N, Brunner P, Koller MT, Ng QK, Maecke HR, Muller-Brand J, Rochlitz C, Briel M, et al. 2014 Somatostatin-based radiopeptide therapy with [177Lu-DOTA]-TOC versus [90Y-DOTA]-TOC in neuroendocrine tumours. European Journal of Nuclear Medicine and Molecular Imaging 41 214-222. (https://doi.org/10.1007/s00259-013-2559-8)

Sorbye H, Welin S, Langer SW, Vestermark LW, Holt N, Osterlund P, Dueland S, Hofsli E, Guren MG, Ohrling K, et al. 2013 Predictive and prognostic factors for treatment and survival in 305 patients with advanced gastrointestinal neuroendocrine carcinoma (WHO G3): the NORDIC NEC study. Annals of Oncology 24 152-160. (https://doi. org/10.1093/annonc/mds276)

Sorbye H, Strosberg J, Baudin E, Klimstra DS \& Yao JC 2014 Gastroenteropancreatic high-grade neuroendocrine carcinoma. Cancer 120 2814-2823. (https://doi.org/10.1002/cncr.28721)

Sorbye H, Baudin E \& Perren A 2018 The problem of high-grade gastroenteropancreatic neuroendocrine neoplasms: welldifferentiated neuroendocrine tumors, neuroendocrine carcinomas, and beyond. Endocrinology and Metabolism Clinics of North America 47 683-698. (https://doi.org/10.1016/j.ecl.2018.05.001)

Strosberg J, El-Haddad G, Wolin E, Hendifar A, Yao J, Chasen B, Mittra E, Kunz PL, Kulke MH, Jacene H, et al. 2017 Phase 3 trial of (177)Lu-dotatate for midgut neuroendocrine tumors. New England Journal of Medicine 376 125-135. (https://doi.org/10.1056/ NEJMoa1607427)
Tang LH, Basturk O, Sue JJ \& Klimstra DS 2016 A practical approach to the classification of WHO grade 3 (G3) well-differentiated neuroendocrine tumor (WD-NET) and poorly differentiated neuroendocrine carcinoma (PD-NEC) of the pancreas. American Journal of Surgical Pathology 40 1192-1202. (https://doi.org/10.1097/ PAS.0000000000000662)

Thang SP, Lung MS, Kong G, Hofman MS, Callahan J, Michael M \& Hicks RJ 2018 Peptide receptor radionuclide therapy (PRRT) in european neuroendocrine tumour society (ENETS) grade 3 (G3) neuroendocrine neoplasia (NEN) - a single-institution retrospective analysis. European Journal of Nuclear Medicine and Molecular Imaging 45 262-277. (https://doi.org/10.1007/s00259-017-3821-2)

Velayoudom-Cephise FL, Duvillard P, Foucan L, Hadoux J, Chougnet CN, Leboulleux S, Malka D, Guigay J, Goere D, Debaere T, et al. 2013 Are G3 ENETS neuroendocrine neoplasms heterogeneous? Endocrine-Related Cancer 20 649-657. (https://doi.org/10.1530/ERC13-0027)

Walter T, Tougeron D, Baudin E, Le Malicot K, Lecomte T, Malka D, Hentic O, Manfredi S, Bonnet I, Guimbaud R, et al. 2017 Poorly differentiated gastro-entero-pancreatic neuroendocrine carcinomas: are they really heterogeneous? Insights from the FFCD-GTE national cohort. European Journal of Cancer 79 158-165. (https://doi. org/10.1016/j.ejca.2017.04.009)

Welin S, Sorbye H, Sebjornsen S, Knappskog S, Busch C \& Oberg K 2011 Clinical effect of temozolomide-based chemotherapy in poorly differentiated endocrine carcinoma after progression on first-line chemotherapy. Cancer 117 4617-4622. (https://doi.org/10.1002/ cncr.26124)

Yamaguchi T, Machida N, Morizane C, Kasuga A, Takahashi H, Sudo K, Nishina T, Tobimatsu K, Ishido K, Furuse J, et al. 2014 Multicenter retrospective analysis of systemic chemotherapy for advanced neuroendocrine carcinoma of the digestive system. Cancer Science 105 1176-1181. (https://doi.org/10.1111/cas.12473)

Zhang J, Kulkarni HR, Singh A, Niepsch K, Muller D \& Baum RP 2018 Peptide receptor radionuclide therapy in grade 3 neuroendocrine neoplasms: safety and survival analysis in 69 patients. Journal of Nuclear Medicine [epub]. (https://doi.org/10.2967/ jnumed.118.215848)

Received in final form 15 November 2018

Accepted 23 November 2018

Accepted Preprint published online 23 November 2018
C) 2019 Society for Endocrinology Published by Bioscientifica Ltd. Printed in Great Britain 